\title{
Changes in Physicochemical and Biological Properties of Polyphenolic-Protein-Polysaccharide Ternary Complexes from Hovenia dulcis after In Vitro Simulated Saliva-Gastrointestinal Digestion
}

\author{
Ding-Tao Wu ${ }^{1,2, *(\mathbb{D})}$, Yuan He ${ }^{2}$, Meng-Xi Fu ${ }^{1,2}$, Ren-You Gan ${ }^{1,3} \mathbb{D}^{\text {, }}$, Yi-Chen Hu ${ }^{1}$ and Liang Zou ${ }^{1, *}$ \\ 1 Key Laboratory of Coarse Cereal Processing (Ministry of Agriculture and Rural Affairs), Sichuan Engineering \\ \& Technology Research Center of Coarse Cereal Industrialization, School of Food and Biological Engineering, \\ Chengdu University, Chengdu 610106, China; mxfu_1996@163.com (M.-X.F.); ganrenyou@caas.cn (R.-Y.G.); \\ huyichen0323@126.com (Y.-C.H.) \\ 2 Institute of Food Processing and Safety, College of Food Science, Sichuan Agricultural University, \\ Ya'an 625014, China; yhsicau@163.com \\ 3 Research Center for Plants and Human Health, Institute of Urban Agriculture, Chinese Academy of \\ Agricultural Sciences, Chengdu 610213, China \\ * Correspondence: DT_Wu@sicau.edu.cn or wudingtao@cdu.edu.cn (D.-T.W.); zouliang@cdu.edu.cn (L.Z.); \\ Tel.: +86-028-8461-6653 (D.-T.W.); +86-028-8461-6061 (L.Z.)
}

Citation: Wu, D.-T.; He, Y.; Fu, M.-X.; Gan, R.-Y.; Hu, Y.-C.; Zou, L. Changes in Physicochemical and Biological Properties of Polyphenolic-ProteinPolysaccharide Ternary Complexes from Hovenia dulcis after In Vitro Simulated Saliva-Gastrointestinal Digestion. Foods 2021, 10, 2322. https: / /doi.org/10.3390/foods 10102322

Academic Editors: Diana Martín and Carolina Cueva

Received: 1 September 2021

Accepted: 27 September 2021

Published: 29 September 2021

Publisher's Note: MDPI stays neutral with regard to jurisdictional claims in published maps and institutional affiliations.

Copyright: (c) 2021 by the authors. Licensee MDPI, Basel, Switzerland. This article is an open access article distributed under the terms and conditions of the Creative Commons Attribution (CC BY) license (https:// creativecommons.org/licenses/by/ $4.0 /)$.

\begin{abstract}
The present study aimed to explore the impacts of in vitro simulated saliva-gastrointestinal digestion on physicochemical and biological properties of the polyphenolic-protein-polysaccharide ternary complex (PPP) extracted from Hovenia dulcis. The results revealed that the in vitro digestion did remarkably affect physicochemical properties of PPP, such as content of reducing sugar release, content of bound polyphenolics, and molecular weight distribution, as well as ratios of compositional monosaccharides and amino acids. In particular, the content of bound polyphenolics notably decreased from $281.93 \pm 2.36$ to $54.89 \pm 0.42 \mathrm{mg} \mathrm{GAE} / \mathrm{g}$, which might be the major reason for the reduction of bioactivities of PPP after in vitro digestion. Molecular weight of PPP also remarkably reduced, which might be attributed to the destruction of glycosidic linkages and the disruption of aggregates. Moreover, although biological activities of PPP obviously decreased after in vitro digestion, the digested PPP (PPP-I) also exhibited remarkable in vitro antioxidant and antiglycation activities, as well as in vitro inhibitory effects against $\alpha$-glucosidase. These findings can help to well understand the digestive behavior of PPP extracted from H. dulcis, and provide valuable and scientific supports for the development of PPP in the industrial fields of functional food and medicine.
\end{abstract}

Keywords: Hovenia dulcis; polyphenolic-protein-polysaccharide; in vitro digestion; physicochemical properties; biological activities

\section{Introduction}

Hovenia dulcis (Rhamnaceae), commonly known as Japanese grape, 'Guai Zao' and 'Zhi Ju', is native to East Asia such as Japan, Korea, and China [1]. It is a delicious and sweet fruit, and it is also widely used as a functional food and a traditional Chinese herb in China [2]. Generally, H. dulcis has a long history been used as a traditional Chinese herb for the treatment of liver disease and alcohol poisoning [1,2]. Recently, a numerous number of in vitro and in vivo studies have demonstrated that $H$. dulcis possesses diverse health-promoting effects, such as anti-diabetic, anti-cancer, anti-oxidant, antiinflammatory, and hepatoprotective effects [3,4]. Usually, these health-promoting effects are correlated to different bioactive ingredients that exist in $H$. dulcis, such as polyphenolicprotein-polysaccharide ternary complexes, polysaccharides, polyphenolics, flavonoids, and saponins [1-3,5-7]. Especially, polyphenolic-protein-polysaccharide ternary complexes 
obtained from $H$. dulcis also possess diverse bioactivities, including anti-oxidant, antiglycation, and anti-diabetic effects [2,5]. Therefore, all the data cited above indicates that the polyphenolic-protein-polysaccharide ternary complex (PPP) from H. dulcis has great potential for the development and application in the healthy food and pharmaceutical industries in terms of strong bioactivities.

Digestion is a multi-stage process for food digestion and absorption in the upper gastrointestinal tract of the human body, including oral cavity, esophagus, stomach, and duodenum [8]. Recently, the simulated saliva-gastrointestinal digestion of active compounds like polysaccharides and proteins has attracted people's attention due to its effective, convenient, and economical properties $[9,10]$. For example, researches have indicated that the saliva-gastrointestinal digestion medium such as $\mathrm{pH}$ value and bile salts, as well as enzymes can affect chemical properties and biological functions of some polysaccharides, such as polysaccharides extracted from Plantago asiatica L. [11] and Inonotus obliquus [12]. Besides, Moyo et al. [13] investigated the digestive behavior of phenolic compounds from Solanum nigrum complex, finding that phenolic compounds reduced after in vitro digestion but bioactivities still retained. Furthermore, Lorieau et al. [14] utilized in vitro digestion model to figure out the digestive properties of whey protein in different structures. However, there are few reports on the digestive properties of naturally occurring binary complexes and ternary complexes, such as polyphenolic-protein and polyphenolic-protein-polysaccharide (PPP). The PPP extracted from $H$. dulcis is exactly one of the naturally ternary complexes, and the effects of human upper gastrointestinal tract system on chemical properties and biological functions of PPP are still unknown.

Therefore, for the first time, this study aimed to broaden knowledge about the impacts of in vitro digestion on PPP extracted from $H$. dulcis. The changes in physicochemical and biological properties of PPP after in vitro digestion were explored to provide useful information for the future application of $H$. dulcis in food and medicine fields.

\section{Materials and Methods}

\subsection{Materials and Chemicals} China.

The fresh peduncles of $H$. dulcis were harvested in AnKang City, Shaanxi Province,

ABTS (2,2-azidobisphenol (3-ethylbenzthiazoline-6-sulphonic acid)), DPPH (2,2-diphenyl1-(2,4,6-trinitrophenyl) hydrazyl), sodium nitroprusside (SNP), BSA (bovine serum albumin), $\alpha$-glucosidase, PMP (1-phenyl-3-methyl-5-pyrazolone), BHT (butylated hydroxytoluene), AG (aminoguanidine), $\mathrm{Vc}_{\mathrm{c}}$ (vitamin C), monosaccharide standards, and amino acid standards were bought from Merck. Analytical grade of other reagents and chemicals were used.

\subsection{Extraction of Polyphenolic-Protein-Polysaccharide Ternary Complexes}

The preparation of the PPP referred to the hot-water extraction method as described in our previous report [5]. Briefly, $10.0 \mathrm{~g}$ of $\mathrm{H}$. dulcis powders were extracted twice with deionized water $(1: 30, w / v)$ at $95{ }^{\circ} \mathrm{C}$ for $3 \mathrm{~h}$. After removing starch and protein by thermal stable $\alpha$-amylase and pancreatin, four volumes of $95 \%$ ethanol $(v / v)$ were used for precipitation of the supernatant overnight at $4{ }^{\circ} \mathrm{C}$. Then, the precipitate was collected, redissolved in distilled water, and then dialyzed against deionized water (molecular weight cutoff at $3500 \mathrm{Da}$ ). Finally, PPP was obtained by freeze drying for further analysis.

\subsection{In Vitro Simulated Saliva-Gastrointestinal Digestion of PPP}

The in vitro digestion of PPP was carried out based on the previous method with slight modifications [15]. The simulated salivary solution (100.0 mL) consisted of KSCN (0.364 g), $\mathrm{NaCl}(3.187 \mathrm{~g}), \mathrm{KCl}(1.629 \mathrm{~g}), \mathrm{NaHCO}_{3}(1.540 \mathrm{~g}), \mathrm{Na}_{2} \mathrm{SO}_{4}$ (1.036 g), $\mathrm{NaH}_{2} \mathrm{PO}_{4}$ $(1.615 \mathrm{~g})$, urea $(0.455 \mathrm{~g})$, and $\alpha$-amylase $(75 \mathrm{U} / \mathrm{mL})$, and mixed with $100.0 \mathrm{~mL}$ of PPP $(20.0 \mathrm{mg} / \mathrm{mL})$, then the mixture was incubated at $37^{\circ} \mathrm{C}$ for $5 \mathrm{~min}$. Subsequently, $200.0 \mathrm{~mL}$ of simulated gastric solution, which composed of $2 \mathrm{~g}$ of pepsin, was added into the salivary juice digested sample. The $\mathrm{pH}$ of the mixed solution was promptly modified to $\mathrm{pH}=2.0$ 
by using $\mathrm{HCl}$, and then incubated at $37^{\circ} \mathrm{C}$ for $2 \mathrm{~h}$. Moreover, the $\mathrm{pH}$ of the saliva-gastric digested solution was modified to $\mathrm{pH}=6.8$ during the intestinal digestion, and a mixed solution of pancreatin $(3.5 \mathrm{mg} / \mathrm{mL})$ and bile salts $(22.0 \mathrm{mg} / \mathrm{mL})$ at a ratio of 3: $10(\mathrm{v} / \mathrm{v})$ was added to the saliva-gastric digested solution. After the intestinal digestion for $2 \mathrm{~h}$, the resulting mixture was boiled in water for $10 \mathrm{~min}$ to ensure inactivation of enzymes, and centrifuged to collected supernatant. Then, an aliquot of $2.0 \mathrm{~mL}$ sample was taken out for determining the content of reducing sugar release after in vitro digestion of PPP. The remaining part was successively precipitated by ethanol, dialyzed (molecular weight cutoff at $3500 \mathrm{Da}$ ), and lyophilized for later use. Finally, the obtained sample was named as PPP-I after the entire in vitro digestion.

\subsection{Physicochemical Characterization of PPP after In Vitro Digestion}

The chemical components, including total polysaccharides, proteins, and uronic acids, as well as bound polyphenolics, were detected according to our formerly reported colorimetric methods [2,5], respectively. Besides, molecular weight distribution was detected by size exclusion chromatography coupled with a multi angle laser light scattering and a refractive index detector (SEC-MALLS-RID, Wyatt Technology Co., Santa Barbara, CA, USA) also referred to the previous study [5], and a Discovery Hybrid Rheometer-1 (TA Instruments, New Castle, DE, USA) was used to detect the apparent viscosities of PPPs referred to the previous study [5]. In addition, the U3000 HPLC system (Thermo Fisher Scientific, Waltham, MA, USA) equipped with a C18 column $(150 \mathrm{~mm} \times 4.6 \mathrm{~mm}, 5 \mu \mathrm{m})$ and a diode array detector followed by PMP derivatization was applied for analyzing monosaccharide compositions and reducing sugars [5]. Moreover, the FT-IR analysis was performed by a Nicolet iS 10 FT-IR (Thermo Fisher Scientific, Waltham, MA, USA) referred to the former method [5]. Finally, amino acid compositions were also detected referred to a former method with slight modifications [2]. In brief, $5.0 \mathrm{~mL}$ of $6 \mathrm{M} \mathrm{HCl}$ was used for the hydrolysis of each sample $(20.0 \mathrm{mg})$ in a sealed tube at $110^{\circ} \mathrm{C}$ for $24 \mathrm{~h}$. Then, the degradations were dried by evaporation, and redissolved in $2.0 \mathrm{~mL}$ of $0.02 \mathrm{M} \mathrm{HCl}$. Finally, an automated amino acid analyzer (HITACHIL-8900, Amino Acid Analyzer, Tokyo, Japan) was used to analyze amino acid compositions of PPPs.

\subsection{Evaluation of In Vitro Antioxidant and Antiglycation Effects, as Well as In Vitro Inhibitory} Effect against $\alpha$-Glucosidase of PPP after In Vitro Digestion

Antioxidant capacity indicators, including ABTS, DPPH, and nitric oxide (NO) radical scavenging activities, as well as ferric reducing antioxidant powers (FRAP) of PPP and PPP-I were determined and compared based on a previous study [5]. Briefly, $200 \mu \mathrm{L}$ of ABTS radical cation solution (absorbance at $734 \mathrm{~nm}, 0.75$ ) was mixed with $20 \mu \mathrm{L}$ of PPP and PPP-I at the concentrations ranged from $0.05 \mathrm{mg} / \mathrm{mL}$ to $0.25 \mathrm{mg} / \mathrm{mL}$, and from $0.60 \mathrm{mg} / \mathrm{mL}$ to $1.00 \mathrm{mg} / \mathrm{mL}$, respectively, and then the mixture was incubated at $30^{\circ} \mathrm{C}$ for $20 \mathrm{~min}$. The absorbance was measured at $734 \mathrm{~nm}$. In addition, $200 \mu \mathrm{L}$ of DPPH solution $(0.35 \mathrm{mM})$ was mixed with $20 \mu \mathrm{L}$ of PPP and PPP-I at the concentrations ranged from $0.05 \mathrm{mg} / \mathrm{mL}$ to $0.25 \mathrm{mg} / \mathrm{mL}$, and from $0.20 \mathrm{mg} / \mathrm{mL}$ to $1.00 \mathrm{mg} / \mathrm{mL}$, respectively, and then the mixture was reacted at $37^{\circ} \mathrm{C}$ for $30 \mathrm{~min}$. The absorbance at $517 \mathrm{~nm}$ was measured. Furthermore, $50 \mu \mathrm{L}$ of sodium nitroprusside $(10 \mathrm{mM})$ was mixed with $450 \mu \mathrm{L}$ of PPP and PPP-I at the concentrations ranged from $0.1 \mathrm{mg} / \mathrm{mL}$ to $0.5 \mathrm{mg} / \mathrm{mL}$, and from $0.2 \mathrm{mg} / \mathrm{mL}$ to $1.0 \mathrm{mg} / \mathrm{mL}$, respectively, and then incubated at $25^{\circ} \mathrm{C}$ for $3 \mathrm{~h}$. Then, $250 \mu \mathrm{L}$ of Griess reagent was added into the mixture. The absorbance was measured at $540 \mathrm{~nm}$. Moreover, $3.0 \mathrm{~mL}$ of FRAP solution was mixed with $100 \mu \mathrm{L}$ of PPP and PPP-I at the concentrations ranged from $0.1 \mathrm{mg} / \mathrm{mL}$ to $0.5 \mathrm{mg} / \mathrm{mL}$, and from $1.0 \mathrm{mg} / \mathrm{mL}$ to $3.0 \mathrm{mg} / \mathrm{mL}$, respectively. After $4 \mathrm{~min}$ of incubation at $37^{\circ} \mathrm{C}$, the absorbance was measured at $593 \mathrm{~nm}$. The positive controls were designated as BHT and vitamin C.

The BSA/glucose model was used to measure the antiglycation activities of PPP and PPP-I referred to a previously reported study [5]. The antiglycation activity of each sample was measured at five concentrations ranged from 0.25 to $4.00 \mathrm{mg} / \mathrm{mL}$. Aminoguanidine (AG) was used as the positive control. 
The inhibitory effect of PPP and PPP-I on $\alpha$-glucosidase was also conducted referred to a reported method [16]. The inhibitory effects against $\alpha$-glucosidase of PPP and PPP-I were detected at the concentrations ranged from $10 \mu \mathrm{g} / \mathrm{mL}$ to $18 \mu \mathrm{g} / \mathrm{mL}$, and from $40 \mu \mathrm{g} / \mathrm{mL}$ to $120 \mu \mathrm{g} / \mathrm{mL}$, respectively. Acarbose was used as the positive control.

\subsection{Statistical Analysis}

Data were expressed as mean \pm standard deviation, which were analyzed by using Origin 9.0 software (Origin Lab Corporation, Northampton, MA, USA). Statistical significances $(p<0.05)$ were carried out by one-way analysis of variance (ANOVA) followed by a Duncan's test.

\section{Results and Discussion}

\subsection{Effects of In Vitro Digestion on Physicochemical Properties of PPP}

3.1.1. Changes in Reducing Sugars, Total Polysaccharides, Total Bound Polyphenolics, and Total Proteins of PPP after In Vitro Digestion

Reducing sugar (CR) content has been used to evaluate the degradation of polysaccharide for a long time and can reveal the breakdown of glycosidic bonds [17]. In this study, the CR content released from PPP raised up to $0.27 \pm 0.02 \mathrm{mg} / \mathrm{mL}$ after in vitro digestion, indicating that the glycoside bonds were broken in PPP, which might be in connection with the enzymes and low $\mathrm{pH}$ value in digestive juices, resulting in the degradation of polysaccharides [8]. Indeed, the major type of reducing sugar was determined as glucose by HPLC analysis. The contents of total polysaccharides and uronic acids in PPP decreased from $43.94 \% \pm 1.52 \%$ to $40.33 \% \pm 4.37 \%$, and from $22.41 \% \pm 1.17 \%$ to $17.68 \% \pm 0.73 \%$, respectively, after in vitro digestion, which was corresponded to the increase of reducing sugar content in the digestive mixture.

Furthermore, a high content $(281.93 \pm 2.36 \mathrm{mg} \mathrm{GAE} / \mathrm{g})$ of bound polyphenolics was observed in PPP, and thirteen individual phenolic compounds, including protocatechuic acid, gallocatechin, p-hydroxybenzoic acid, ampelopsin, quercetin-7,4'-diglucoside, quercetin, rutin, dihydroquercetin, myricitrin, myricetin, kaempferol, 5-methylmyricetin, and naringenin were identified in PPP [2,5]. Therefore, we investigated the impact of in vitro digestion on the stability of bound polyphenolics in PPP. Results showed that in vitro digestion could also remarkably affect the content of polyphenolic in PPP. As shown in Table 1, after in vitro digestion, the content of total bound polyphenolics remarkably reduced from $281.93 \pm 2.36$ to $54.89 \pm 0.42 \mathrm{mg} \mathrm{GAE} / \mathrm{g}$, indicating that bound polyphenolics were released from PPP during in vitro digestion. Similar results were also found in previous studies [18-20]. The low $\mathrm{pH}$ around 2.0 and the pepsin action in the gastric digestion did have an influence on the stability of bound polyphenolics $[19,21]$. Additionally, some polyphenolics will be degraded during the transition from the acidic gastric conditions to the mild alkaline intestinal conditions, especially under the influence of bile acids and pancreatin [22].

Table 1. Changes in reducing sugar content and chemical compositions of PPP after in vitro digestion.

\begin{tabular}{ccc}
\hline & PPP & PPP-I \\
\hline Reducing sugar content (mg/mL) & & $0.27 \pm 0.02$ \\
Total polysaccharides (\%) & $40.33 \pm 4.37^{\mathrm{a}}$ \\
Total uronic acids (\%) & $22.41 \pm 1.17^{\mathrm{a}}$ & $17.68 \pm 0.73^{\mathrm{b}}$ \\
Total polyphenolics (mg GAE/g) & $281.93 \pm 2.36^{\mathrm{a}}$ & $54.89 \pm 0.42^{\mathrm{b}}$ \\
Total protein (\%) & $17.62 \pm 0.75^{\mathrm{b}}$ & $22.43 \pm 0.89^{\mathrm{a}}$ \\
\hline
\end{tabular}

$\overline{\text { PPP, polyphenolic-protein-polysaccharide ternary complexes from Hovenia dulcis; PPP-I, indicated PPP after }}$ in vitro digestion; Values represent mean \pm standard deviation, and different superscript lowercase letters $(a-b)$ indicated significance $(p<0.05)$ in each row. Statistical significances $(p<0.05)$ were carried out by one-way analysis of variance (ANOVA) followed by a Duncan's test.

Moreover, due to the decrease of total polysaccharides and total bound polyphenolics, the proportion of proteins in PPP increased by $27.30 \%$ after in vitro digestion. Results 
suggested that the protein was relatively more stable compared with polysaccharides and bound polyphenolics. Previous studies have shown that phenolic compounds could impact on protein digestibility as they exhibited strong binding ability with proteins [23,24].

3.1.2. Changes in Molecular Weight and Apparent Viscosity of PPP after In Vitro Digestion

In general, the molecular weight $\left(M_{w}\right)$ and apparent viscosity are vital characteristics of natural polysaccharides which can affect their biological activities [5]. Thus, the impacts of in vitro digestion on the $M_{w}$ and apparent viscosity of PPP were explored. Figure 1A shows the HPSEC-RID-UV chromatograms of PPP and PPP-I. As seen in Table 2, molecular weights of fraction 1 in PPP were detected as $5.97 \times 10^{4} \mathrm{Da}$. However, after in vitro digestion, the molecular weight of PPP changed markedly. It was obvious that the fraction 1 (16 $\mathrm{min}$ to $22 \mathrm{~min}$ ) of PPP degraded into the fraction 2 (16 $\mathrm{min}$ to $21 \mathrm{~min}$ ) and fraction 3 (21 $\mathrm{min}$ to $22 \mathrm{~min}$ ) of PPP-I after in vitro digestion. Moreover, the molecular weights of two fractions in PPP-I remarkably decreased to $4.68 \times 10^{4}$ Da and $1.39 \times 10^{4}$ Da when compared with PPP. The reduction of molecular weight of PPP may be caused by the destruction of glycosidic bonds according to the obvious increase of reducing sugar content after in vitro digestion [25]. It is in accord with former studies, which suggested that natural polysaccharides could be degraded in the digestive juices [26]. In addition, the remarkable decrease of bound polyphenolics might also contribute to the decrease of its molecular weight due to the disruption of aggregates [27].

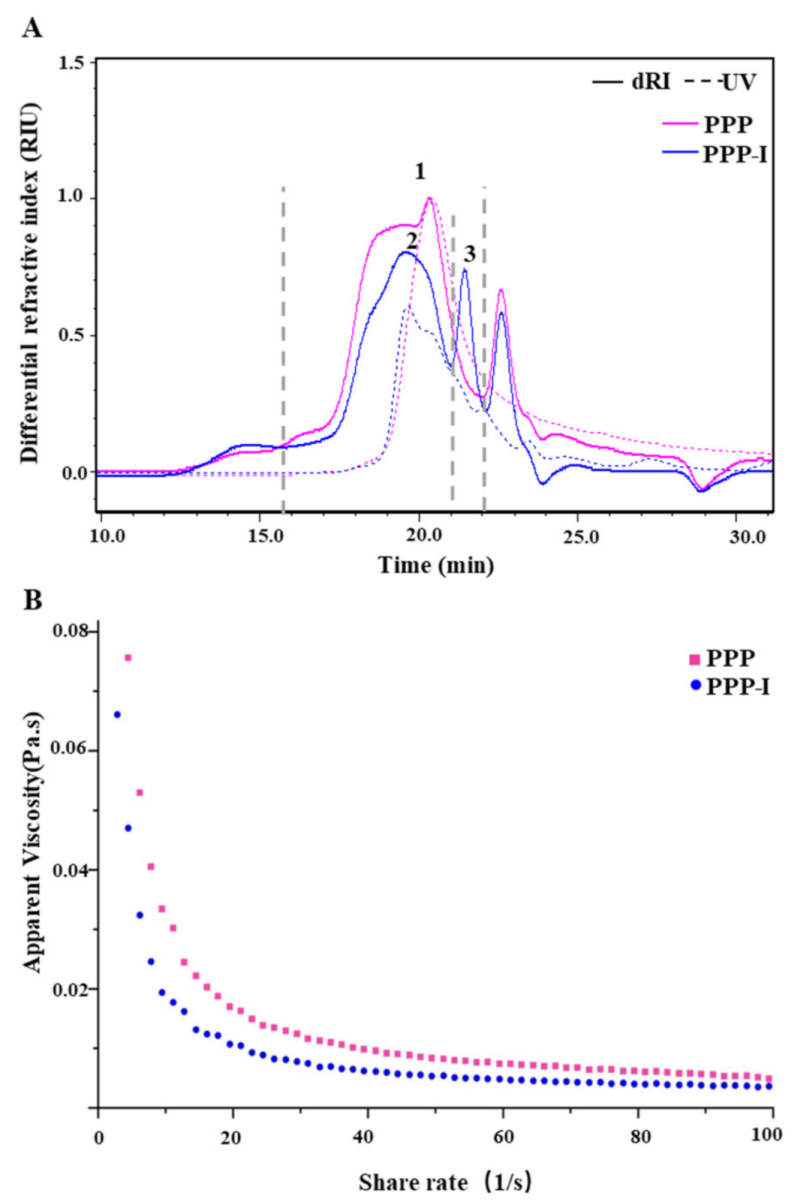

Figure 1. Changes in HPSEC chromatogram (A) and apparent viscosity (B) of PPP after in vitro digestion. PPP, polyphenolic-protein-polysaccharide ternary complexes from Hovenia dulcis; PPP-I, indicated PPP after in vitro digestion. 
Table 2. Changes in molecular weight $\left(M_{w}\right)$, polydispersity $\left(M_{w} / M_{n}\right)$, and monosaccharide compositions of PPP after in vitro digestion.

\begin{tabular}{ccc}
\hline & PPP & PPP-I \\
\hline$M_{w} \times 10^{4}(\mathrm{Da})$ & & \\
Peak 1 & $5.97( \pm 0.59 \%)$ & \\
Peak 2 & & $4.68( \pm 1.21 \%)$ \\
Peak 3 & & $1.39( \pm 4.34 \%)$ \\
$M_{w} / M_{n}$ & $1.76( \pm 1.11 \%)$ & \\
Peak 1 & & $1.50( \pm 2.29 \%)$ \\
Peak 2 & & $1.07( \pm 4.59 \%)$ \\
Peak 3 & & \\
Galactose & 1.00 & 1.00 \\
Galacturonic acid & 1.78 & 1.30 \\
Arabinose & 1.12 & 1.11 \\
Glucose & 0.96 & 0.34 \\
Rhamnose & 0.64 & 0.83 \\
Mannose & 0.15 & 0.11 \\
Glucuronic acid & 0.07 & 0.06 \\
Xylose & 0.06 & 0.06 \\
\hline
\end{tabular}

PPP, polyphenolic-protein-polysaccharide ternary complexes from Hovenia dulcis; PPP-I, indicated PPP after in vitro digestion. The peaks were the same as in Figure 1.

As shown in Figure 1B, it could be observed that the shear rate made a difference to the apparent viscosities of PPP and PPP-I solution. Both of them possessed shear-thinning and Newtonian fluid behaviors. In addition, a decrease of apparent viscosity of PPP was observed after in vitro digestion. Generally, the apparent viscosity of natural polysaccharides is related to their chemical structure, such as molecular weight distribution and degree of esterification [28]. Therefore, the decrease of apparent viscosity might be corresponded to the reduction of molecular weight of PPP after in vitro saliva-gastrointestinal digestion.

\subsubsection{Changes in Monosaccharide Compositions and FT-IR Spectra of PPP after In} Vitro Digestion

It is universally acknowledged that biological functions of natural polysaccharides are also affected by their monosaccharide compositions and molar ratios [27]. Therefore, we also investigated the monosaccharide composition of PPP after in vitro digestion. Figure 2A presents the chromatography profiles of monosaccharides in PPP and PPP-I. The results demonstrated that the monosaccharides in PPP and PPP-I were similar, which mainly consisted of galacturonic acid (GalA), galactose (Gal), arabinose (Ara), glucose (Glc), rhamnose (Rha), mannose (Man), glucuronic acid (GlcA), and xylose (Xyl). Furthermore, GalA, Gal, Ara, Glc, and Rha were determined as the dominant monosaccharides, which were consistent with a previous study [5]. However, their molar ratios had some changes. For instance, after in vitro digestion, the molar ratio of GalA reduced from 1.78 to 1.30, which corresponded to an obvious reduction in total uronic acids (Table 1). Additionally, the molar ratio of Glc also decreased from 0.96 to 0.34 . To sum up, results suggested that the types of monosaccharides of PPP were not affected by the saliva-gastrointestinal digestion, but the molar ratios were changed after in vitro digestion.

The primary functional groups of PPP and PPP-I were further evaluated by FT-IR spectroscopy. Figure 2B showed that the FT-IR spectra of PPP and PPP-I were similar, which meant the major functional groups of PPP had no remarkable changes after the saliva-gastrointestinal digestion. Specifically, the strong absorption band around $3416 \mathrm{~cm}^{-1}$ could be attributed to the stretching vibrations of $-\mathrm{OH}$, while the relatively band peak at approximately $2938 \mathrm{~cm}^{-1}$ was the result of C-H vibration [7]. The band at $1743 \mathrm{~cm}^{-1}$ was attributed to be stretching vibration of carboxylic ester $(\mathrm{C}=\mathrm{O})$ [5]. Besides, the band that appeared around $1620 \mathrm{~cm}^{-1}$ was due to the stretching vibration of $\mathrm{C}=\mathrm{O}$ asymmetric stretching of ionic carboxyl groups (COO-), suggesting the presence of uronic acids in PPP 
and PPP-I [1]. The absorption bands at $1620 \mathrm{~cm}^{-1}$ and $1558 \mathrm{~cm}^{-1}$ that recognized as the amide I and amide II regions were also observed [5]. Furthermore, the band at $1419 \mathrm{~cm}^{-1}$ was attributed to $C=C$ stretching vibrations of aromatic ring $[2,5]$.
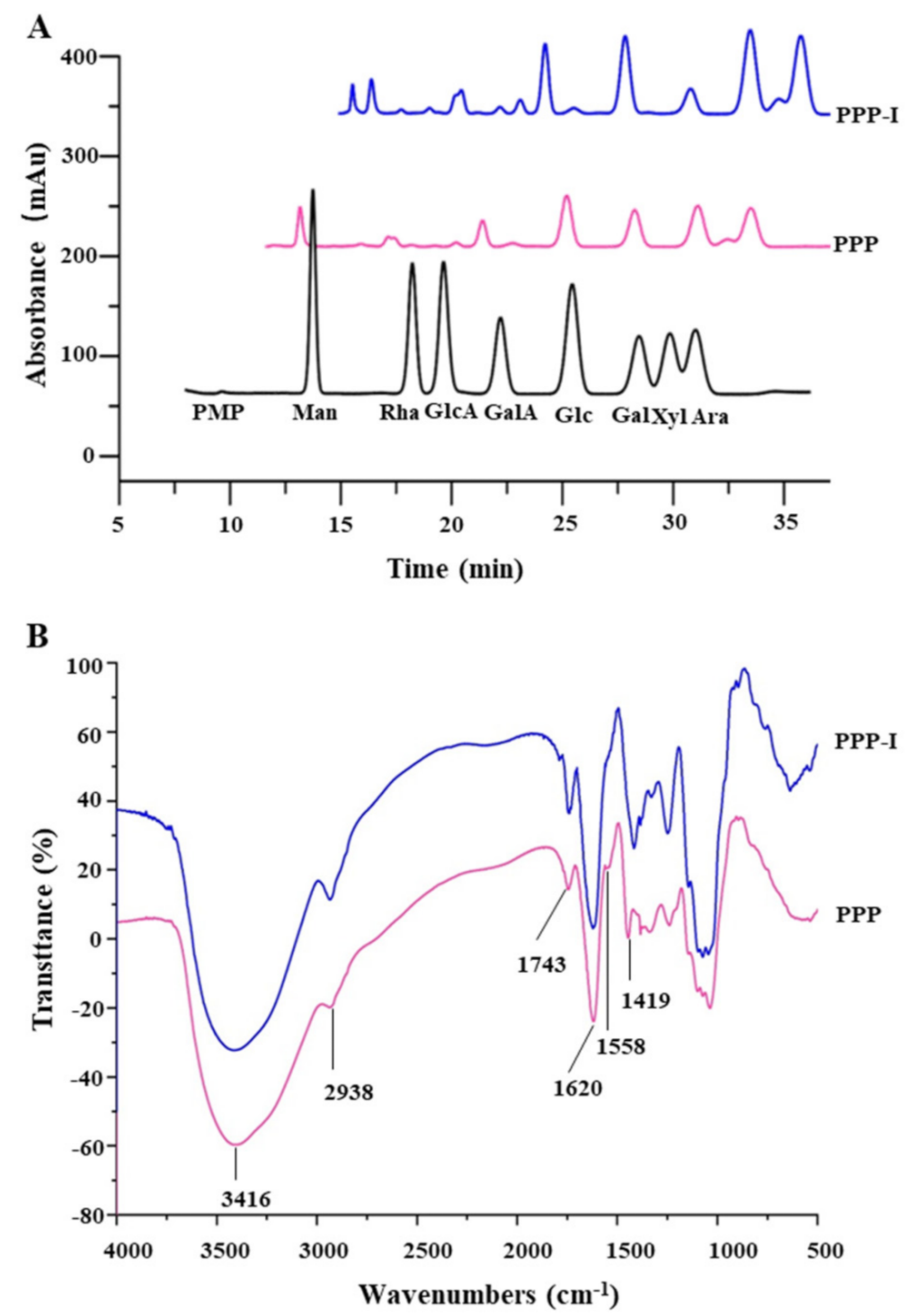

Figure 2. Changes in monosaccharide compositions (A) and FT-IR spectra (B) of PPP after in vitro digestion. PPP, polyphenolic-protein-polysaccharide ternary complexes from Hovenia dulcis; PPP-I, indicated PPP after in vitro digestion.

\subsubsection{Changes in Amino Acid Compositions of PPP after In Vitro Digestion}

As presented in Table 3, the protein fraction of PPP and PPP-I contained a total of 17 types of amino acids. The results indicated that the amino acid compositions in PPP and PPP-I were similar, and glutamic acid, aspartic acid, proline, serine, glycine, threonine, leucine, and alanine were determined as predominant amino acids in both PPP and PPP-I. However, contents of several amino acids in PPP obviously changed after in vitro digestion. For instance, the ratio of aspartic acid increased from $9.65 \%$ to $13.28 \%$ after in vitro digestion, which could be used as a carrier of potassium and magnesium ions to improve the myocardial systolic function and protect the myocardium [29]. Similarly, the ratio of lysine increased greatly as well, which could enhance the immune system, and promote bone and prevent osteoporosis combined with other amino acids [30]. Commonly, essential amino acids cannot be synthesized in the human body and must be obtained from 
daily food. Thus, the quality of protein usually depends on the content of essential amino acids [31]. However, the ratio of essential amino acids decreased from $41.59 \%$ to $36.49 \%$ after in vitro saliva-gastrointestinal digestion, indicating that some essential amino acids might be destroyed by the acid hydrolysis catalyzed by pepsin during in vitro digestion.

Table 3. Amino acid compositions of PPP and PPP-I.

\begin{tabular}{ccc}
\hline Amino Acids & PPP (\%) & PPP-I (\%) \\
\hline Glutamic acid & $12.50 \pm 0.59^{\mathrm{a}}$ & $13.19 \pm 0.55^{\mathrm{a}}$ \\
Aspartic acid & $9.65 \pm 0.44^{\mathrm{b}}$ & $13.28 \pm 0.62^{\mathrm{a}}$ \\
Proline & $8.83 \pm 0.41^{\mathrm{a}}$ & $6.68 \pm 0.31^{\mathrm{b}}$ \\
Leucine & $8.30 \pm 0.40^{\mathrm{a}}$ & $5.33 \pm 0.24^{\mathrm{b}}$ \\
Serine & $7.61 \pm 0.37^{\mathrm{a}}$ & $7.44 \pm 0.32^{\mathrm{a}}$ \\
Glycine & $7.59 \pm 0.32^{\mathrm{b}}$ & $9.80 \pm 0.41^{\mathrm{a}}$ \\
Tyrosine & $7.30 \pm 0.22^{\mathrm{a}}$ & $3.11 \pm 0.12^{\mathrm{b}}$ \\
Threonine & $6.92 \pm 0.33^{\mathrm{a}}$ & $6.98 \pm 0.32^{\mathrm{a}}$ \\
Isoleucine & $6.26 \pm 0.21^{\mathrm{a}}$ & $3.90 \pm 0.17^{\mathrm{b}}$ \\
Alanine & $6.08 \pm 0.30^{\mathrm{a}}$ & $6.46 \pm 0.27^{\mathrm{a}}$ \\
Valine & $4.73 \pm 0.23^{\mathrm{a}}$ & $4.99 \pm 0.23^{\mathrm{a}}$ \\
Phenylalanine & $4.38 \pm 0.11^{\mathrm{a}}$ & $4.61 \pm 0.13^{\mathrm{a}}$ \\
Arginine & $3.69 \pm 0.17^{\mathrm{a}}$ & $3.11 \pm 0.14^{\mathrm{b}}$ \\
Lysine & $3.49 \pm 0.13^{\mathrm{b}}$ & $6.07 \pm 0.28^{\mathrm{a}}$ \\
Cystine & $1.39 \pm 0.05^{\mathrm{a}}$ & $0.84 \pm 0.03^{\mathrm{b}}$ \\
Histidine & $1.08 \pm 0.04^{\mathrm{b}}$ & $2.71 \pm 0.13^{\mathrm{a}}$ \\
Methionine & $0.20 \pm 0.01^{\mathrm{b}}$ & $1.47 \pm 0.07^{\mathrm{a}}$ \\
Essential amino acids & $41.59 \pm 2.01^{\mathrm{a}}$ & $36.49 \pm 1.76^{\mathrm{b}}$ \\
Non-essential amino acids & $58.41 \pm 1.92^{\mathrm{b}}$ & $63.51 \pm 2.14^{\mathrm{a}}$ \\
\hline
\end{tabular}

$\overline{\text { PPP, polyphenolic-protein-polysaccharide ternary complexes from Hovenia dulcis; PPP-I, indicated PPP after }}$ in vitro digestion. Values represent mean \pm standard deviation, and different superscript lowercase letters $(a-b)$ indicated significance $(p<0.05)$ in each row. Statistical significances $(p<0.05)$ were carried out by one-way analysis of variance (ANOVA) followed by a Duncan's test.

\subsection{Effects of In Vitro Simulated Saliva-Gastrointestinal Digestion on Biological Functions of PPP}

\subsubsection{Stability of Antioxidant Activities of PPP after In Vitro Digestion}

Previous studies have found that polyphenolic-protein-polysaccharide ternary complexes from $H$. dulcis possessed high antioxidant capacity [2,5]. Hence, the effect of in vitro digestion on the antioxidant ability of PPP was evaluated by different antioxidant assays in the present study, namely ABTS, DPPH, and NO radical scavenging activities, as well as ferric reducing antioxidant powers (FRAP). Figure 3 shows the stability of ABTS, DPPH, and NO radical scavenging activities, as well as FRAP of PPP after in vitro digestion. Compared with the positive controls, experimental results indicated that PPP and PPP-I possessed remarkable antioxidant abilities. The $\mathrm{IC}_{50}$ values of $\mathrm{ABTS}, \mathrm{DPPH}$, and NO radical scavenging activities of PPP and PPP-I were calculated and ranged from 0.125 to $0.826 \mathrm{mg} / \mathrm{mL}$, from 0.104 to $0.547 \mathrm{mg} / \mathrm{mL}$, and from 0.217 to $0.480 \mathrm{mg} / \mathrm{mL}$, respectively. After in vitro digestion, the antioxidant activities of PPP have reduced sharply (Figure 3), suggesting that the antioxidant activities of PPP were quite unstable during in vitro digestion. The decrease of antioxidant activities of PPP might be corresponded to the changes of its physicochemical properties during in vitro digestion. Obviously, the FRAP of PPP-I was also obviously lower than that of PPP (Figure 3D).

Generally, chemical structures, $M_{w}$, and monosaccharide compositions especially uronic acids of polysaccharides can affect their in vitro antioxidant activities [32]. Indeed, for the polyphenolic-protein-polysaccharide complexes, their antioxidant activities are also closely related to polyphenolics and proteins [2,5]. Polyphenolics can neutralize free radicals by donating an electron or hydrogen atom due to their highly conjugated system and hydroxylation patterns, and reduce the rate of oxidation by suppressing the generation of free radicals, or by deactivation of the reactive species and precursors of free radicals [33]. Besides, some amino acids, such as lysine, histidine, and tyrosine, have been attested to 
be capable of donating protons to electron-deficient radicals $[5,34]$. Therefore, the sharp reduction in antioxidant activities of PPP after in vitro digestion might be associated with the decrease of uronic acids and polyphenolics. Besides, it might also be related to the changes of protein to some extent. For instance, after in vitro digestion, the content of Tyr remarkably decreased from $7.30 \%$ to $3.11 \%$.
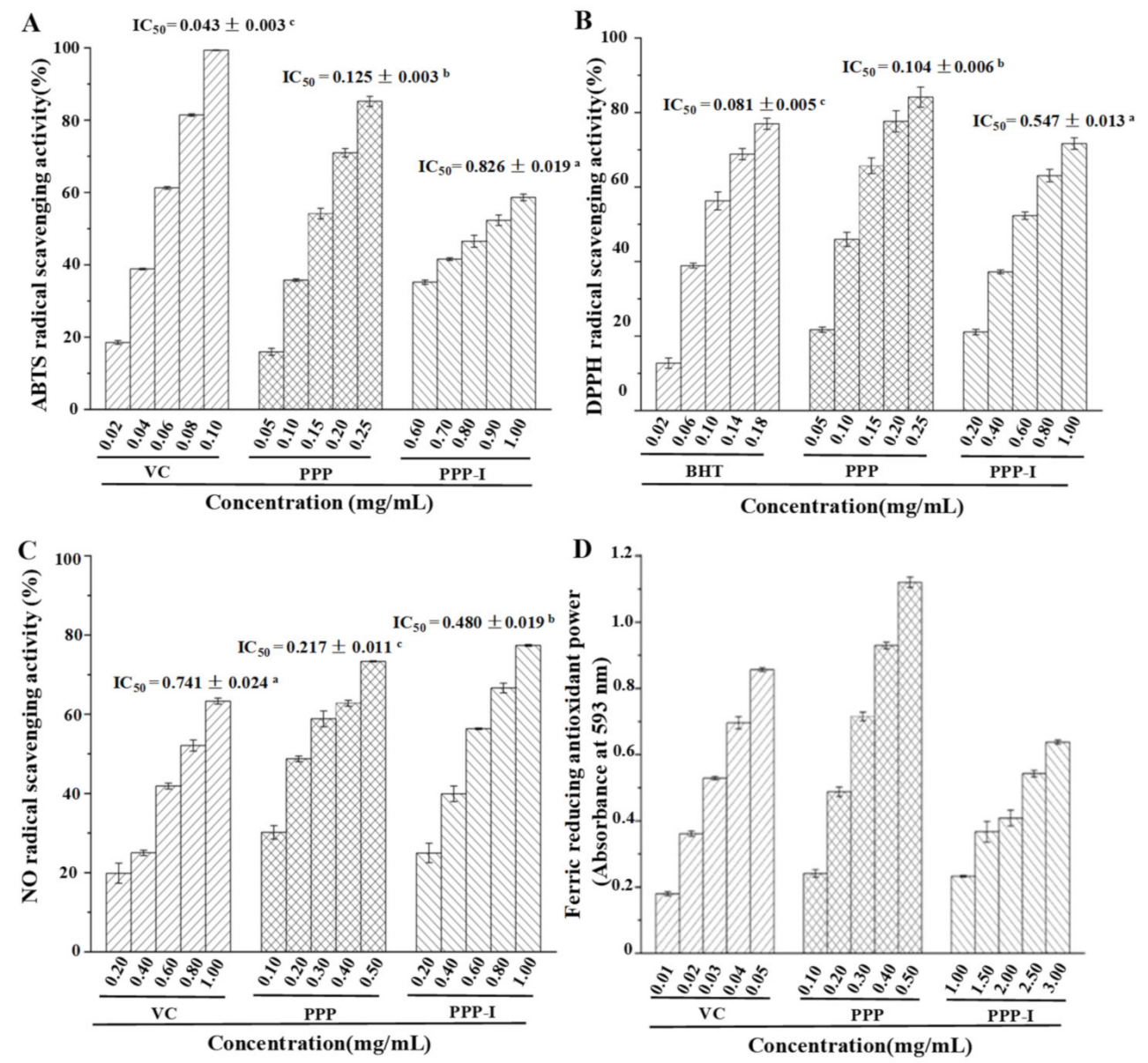

Figure 3. Stability of ABTS (A), DPPH (B), NO (C), and FRAP (D) antioxidant capacities of PPP after in vitro digestion. PPP, polyphenolic-protein-polysaccharide ternary complexes from Hovenia dulcis; PPP-I, indicated PPP after in vitro digestion. BHT, butylated hydroxytoluene; Vc, vitamin C. The error bars are standard deviations; Different superscript lowercase letters $(\mathbf{a}-\mathbf{c})$ indicated significance $(p<0.05)$. Statistical significances $(p<0.05)$ were carried out by one-way analysis of variance (ANOVA) followed by a Duncan's test.

\subsubsection{Stability of Antiglycation Activity of PPP after In Vitro Digestion}

Glycosylation is a spontaneous non-enzymatic amino-carbonyl reaction between reducing sugars and proteins, and then forms advanced glycation end products (AGEs) which can lead to aging and arteriosclerosis [35]. Therefore, the inhibition of AGEs formation of natural products has attracted considerable attention. As shown in Figure 4, both PPP and PPP-I possessed strong inhibitory effects against the formation of AGEs when compared with the positive control. The $\mathrm{IC}_{50}$ values of inhibitory activities against the formation of AGEs of PPP and PPP-I were determined to be $0.532 \mathrm{mg} / \mathrm{mL}$ and $1.465 \mathrm{mg} / \mathrm{mL}$, respectively, indicating that the inhibitory effect of PPP against the formation of AGEs significantly decreased after in vitro digestion. Former reports have proven that the oxidation is the main reason for the formation of AGEs, and the high antiglycation activity may be associated with its strong antioxidant activity and high content of polyphenolics [36]. Therefore, the significant decrease in antiglycation activity of PPP after in vitro 
digestion might be related to the reduction of its antioxidant activities and the decrease of its total polyphenolics.

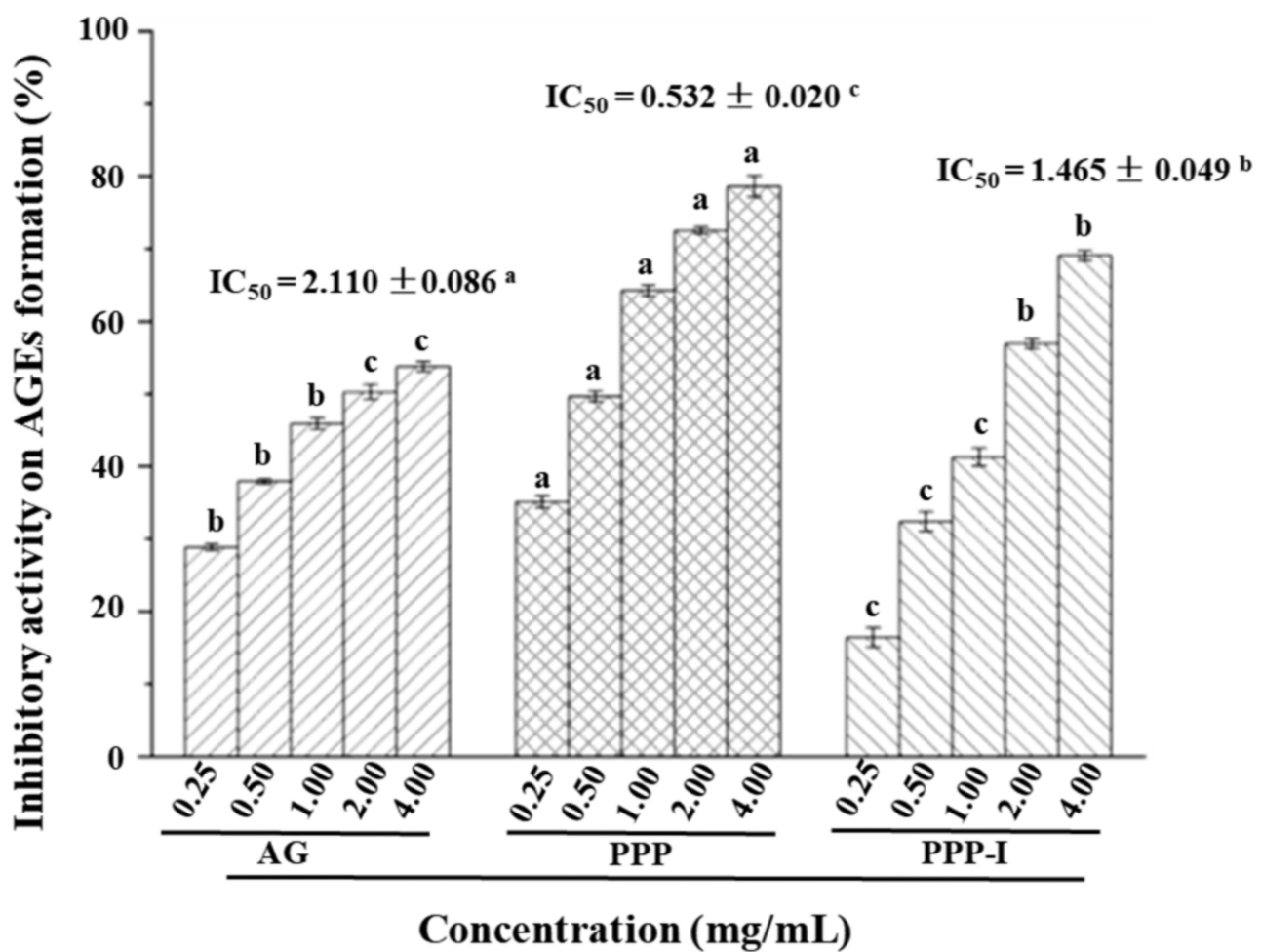

Figure 4. Stability of antiglycation activity of PPP after in vitro digestion. PPP, polyphenolic-proteinpolysaccharide ternary complexes from Hovenia dulcis; PPP-I, indicated PPP after in vitro digestion; AG, aminoguanidine; The error bars are standard deviations; Significant $(p<0.05)$ differences among AG, PPP, and PPP-I are shown by data bearing different letters $(\mathbf{a}-\mathbf{c})$. Statistical significances $(p<0.05)$ were carried out by one-way analysis of variance (ANOVA) followed by a Duncan's test.

\subsubsection{Stability of Inhibitory Activity against $\alpha$-Glucosidase of PPP after In Vitro Digestion}

As an important enzyme for carbohydrate digestion, $\alpha$-glycosidase inhibitor can resist metabolic changes related to hyperglycemia and type 2 diabetes on account delaying the release of glucose and control the postprandial hyperglycemia [37]. Previous studies have found that $H$. dulcis exhibits strong in vitro anti-diabetic effects [6]. Hence, the influence of in vitro digestion on the $\alpha$-glucosidase inhibitory effect of PPP was investigated. As shown in Figure 5 , the $\mathrm{IC}_{50}$ values of $\alpha$-glucosidase inhibitory effect of PPP and PPP-I were $0.013 \mathrm{mg} / \mathrm{mL}$ and $0.101 \mathrm{mg} / \mathrm{mL}$, respectively, suggesting that both PPP and PPP-I exerted remarkable inhibitory effects against $\alpha$-glucosidase compared with the positive control (acarbose, $\mathrm{IC}_{50}=2.876 \mathrm{mg} / \mathrm{mL}$ ). However, after in vitro digestion, the $\alpha$-glucosidase inhibitory effect of PPP obviously decreased. A previous study showed that flavonoids extracted from $H$. dulcis exhibited strong $\alpha$-glycosidase inhibitory effect [6]. Meanwhile, the high contents of uronic acids and total polyphenolics of PPP could contribute to its strong $\alpha$-glucosidase inhibitory effect [5]. In addition, the high molecular weight might be also related to the remarkable inhibitory effect of polysaccharide on $\alpha$-glucosidase [32,38]. Therefore, the reduction in $\alpha$-glucosidase inhibitory effect of PPP after in vitro digestion might be associated with the decrease of its molecular weight and total polyphenolics. 


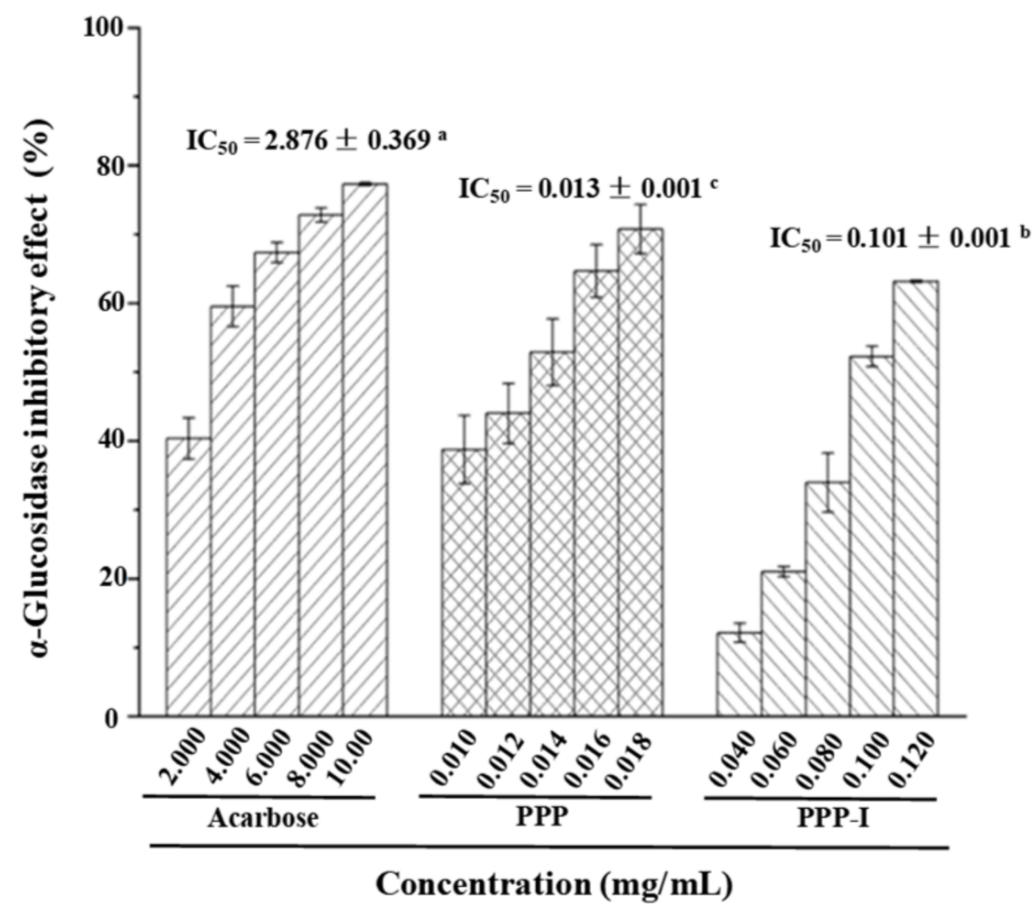

Figure 5. Stability of inhibitory effect on $\alpha$-glucosidase of PPP after in vitro digestion. PPP, polyphenolic-protein-polysaccharide ternary complexes from Hovenia dulcis; PPP-I, indicated PPP after in vitro digestion; The error bars are standard deviations; Different superscript lowercase letters $(\mathbf{a}-\mathbf{c})$ indicated significance $(p<0.05)$. Statistical significances $(p<0.05)$ were carried out by one-way analysis of variance (ANOVA) followed by a Duncan's test.

\section{Conclusions}

In the present study, the in vitro digestion on physicochemical and biological properties of polyphenolic-protein-polysaccharide ternary complexes from $H$. dulcis was investigated. Physicochemical properties of PPP, including contents of reducing sugar release, bound polyphenolics, proteins, and uronic acids, and molecular weight distribution, as well as ratios of monosaccharides and amino acids, obviously changed after in vitro digestion. Meanwhile, the antioxidant activities, antiglycation activity, and inhibitory effect on $\alpha$-glucosidase of PPP notably decreased after in vitro digestion, which might be largely related to the remarkable decrease of bound polyphenolics. Results from this study can contribute to a better understanding of the potential digestive mechanism of PPP extracted from $H$. dulcis, which possess important implications for the development of PPP as functional foods and medicines.

Author Contributions: Conceptualization, D.-T.W. and L.Z.; methodology, Y.H. and D.-T.W.; validation, M.-X.F.; formal analysis, D.-T.W., Y.H., M.-X.F. and L.Z.; investigation, Y.H., D.-T.W. and M.-X.F.; resources, R.-Y.G. and Y.-C.H.; data curation, D.-T.W. and Y.H.; writing-original draft preparation, D.-T.W. and Y.H.; writing-review and editing, D.-T.W. and L.Z.; supervision, D.-T.W. and L.Z.; project administration, L.Z.; funding acquisition, D.-T.W. All authors have read and agreed to the published version of the manuscript.

Funding: This work was supported by the Scientific Research Foundation of Chengdu University (No. 2081921047), and the National Natural Science Foundation of China (No. 31901690).

Institutional Review Board Statement: Not applicable.

Informed Consent Statement: Not applicable.

Data Availability Statement: Not applicable.

Conflicts of Interest: The authors declare no conflict of interest. 


\section{References}

1. Yang, B.; Wu, Q.J.; Luo, Y.X.; Yang, Q.; Chen, G.J.; Wei, X.Y.; Kan, J.Q. Japanese grape (Hovenia dulcis) polysaccharides: New insight into extraction, characterization, rheological properties, and bioactivities. Int. J. Biol. Macromol. 2019, 134, 631-644. [CrossRef]

2. Wu, D.T.; Liu, W.; Xian, M.L.; Du, G.; Liu, X.; He, J.J.; Wang, P.; Qin, W.; Zhao, L. Polyphenolic-protein-polysaccharide complexes from Hovenia dulcis: Insights into extraction methods on their physicochemical properties and in vitro bioactivities. Foods 2020, 9 , 456. [CrossRef]

3. Sferrazza, G.; Brusotti, G.; Zonfrillo, M.; Temporini, C.; Tengattini, S.; Bononi, M.; Tateo, F.; Calleri, E.; Pierimarchi, P. Hovenia dulcis Thumberg: Phytochemistry, pharmacology, toxicology and regulatory framework for its use in the European Union. Molecules 2021, 26, 903. [CrossRef]

4. Hyun, T.K.; Eom, S.H.; Yu, C.Y.; Roitsch, T. Hovenia dulcis-An Asian traditional herb. Planta Med. 2010, 76, 943-949. [CrossRef]

5. Liu, W.; Li, F.; Wang, P.; Liu, X.; He, J.J.; Xian, M.L.; Zhao, L.; Qin, W.; Gan, R.Y.; Wu, D.T. Effects of drying methods on the physicochemical characteristics and bioactivities of polyphenolic-protein-polysaccharide conjugates from Hovenia dulcis. Int. J. Biol. Macromol. 2020, 148, 1211-1221. [CrossRef]

6. Meng, Y.H.; Su, A.P.; Yuan, S.; Zhao, H.G.; Tan, S.Y.; Hu, C.Y.; Deng, H.; Guo, Y.R. Evaluation of total flavonoids, myricetin, and quercetin from Hovenia dulcis Thunb. As inhibitors of $\alpha$-amylase and $\alpha$-glucosidase. Plant Food. Hum. Nutr. 2016, 71, 444-449. [CrossRef]

7. Yang, B.; Wu, Q.J.; Luo, Y.X.; Yang, Q.; Chen, G.J.; Wei, X.Y.; Kan, J.Q. High-pressure ultrasonic-assisted extraction of polysaccharides from Hovenia dulcis: Extraction, structure, antioxidant activity and hypoglycemic. Int. J. Biol. Macromol. 2019, 137, 676-687. [CrossRef] [PubMed]

8. Zhu, K.X.; Yao, S.W.; Zhang, Y.J.; Liu, Q.B.; Xu, F.; Wu, G.; Dong, W.J.; Tan, L.H. Effects of in vitro saliva, gastric and intestinal digestion on the chemical properties, antioxidant activity of polysaccharide from Artocarpus heterophyllus Lam. (Jackfruit) Pulp. Food Hydrocoll. 2019, 87, 952-959. [CrossRef]

9. Li, C.; Yu, W.W.; Wu, P.; Chen, X.D. Current in vitro digestion systems for understanding food digestion in human upper gastrointestinal tract. Trends Food Sci. Technol. 2020, 96, 114-126. [CrossRef]

10. Ji, H.H.; Hu, J.L.; Zuo, S.; Zhang, S.S.; Li, M.Z.; Nie, S.P. In vitro gastrointestinal digestion and fermentation models and their applications in food carbohydrates. Crit. Rev. Food Sci. Nutr. 2021. [CrossRef]

11. Hu, J.L.; Nie, S.P.; Min, F.F.; Xie, M.Y. Artificial simulated saliva, gastric and intestinal digestion of polysaccharide from the seeds of Plantago asiatica L. Carbohydr. Polym. 2013, 92, 1143-1150. [CrossRef]

12. Wang, C.; Li, W.W.; Chen, Z.Q.; Gao, X.D.; Yuan, G.Q.; Pan, Y.X.; Chen, H.X. Effects of simulated gastrointestinal digestion in vitro on the chemical properties, antioxidant activity, $\alpha$-amylase and $\alpha$-glucosidase inhibitory activity of polysaccharides from Inonotus obliquus. Food Res. Int. 2018, 103, 280-288. [CrossRef]

13. Moyo, S.M.; Serem, J.C.; Bester, M.J.; Mavumengwana, V.; Kayitesi, E. The impact of boiling and in vitro human digestion of Solanum nigrum complex (Black nightshade) on phenolic compounds bioactivity and bioaccessibility. Food Res. Int. 2020, 137, 109720. [CrossRef]

14. Lorieau, L.; Halabi, A.; Ligneul, A.; Hazart, E.; Dupont, D.; Floury, J. Impact of the dairy product structure and protein nature on the proteolysis and amino acid bioaccessiblity during in vitro digestion. Food Hydrocoll. 2018, 82, 399-411. [CrossRef]

15. Wu, D.T.; Yuan, Q.; Guo, H.; Fu, Y.; Li, F.; Wang, S.P.; Gan, R.Y. Dynamic changes of structural characteristics of snow chrysanthemum polysaccharides during in vitro digestion and fecal fermentation and related impacts on gut microbiota. Food Res. Int. 2021, 141, 109888. [CrossRef] [PubMed]

16. Fu, Y.; Yuan, Q.; Lin, S.; Liu, W.; Du, G.; Zhao, L.; Zhang, Q.; Lin, D.R.; Liu, Y.T.; Qin, W.; et al. Physicochemical characteristics and biological activities of polysaccharides from the leaves of different loquat (Eriobotrya japonica) cultivars. Int. J. Biol. Macromol. 2019, 135, 274-281. [CrossRef] [PubMed]

17. Fu, Y.; Li, F.; Ding, Y.; Li, H.Y.; Xiang, X.R.; Ye, Q.; Zhang, J.; Zhao, L.; Qin, W.; Gan, R.Y.; et al. Polysaccharides from loquat (Eriobotrya japonica) leaves: Impacts of extraction methods on their physicochemical characteristics and biological activities. Int. J. Biol. Macromol. 2020, 146, 508-517. [CrossRef] [PubMed]

18. Gunathilake, K.D.P.P.; Ranaweera, K.K.D.S.; Rupasinghe, H.P.V. Change of phenolics, carotenoids, and antioxidant capacity following simulated gastrointestinal digestion and dialysis of selected edible green leaves. Food Chem. 2018, 245, 371-379. [CrossRef]

19. Qin, Y.; Wang, L.; Liu, Y.F.; Zhang, Q.Y.; Li, Y.X.; Wu, Z.Q. Release of phenolics compounds from Rubus idaeus L. dried fruits and seeds during simulated in vitro digestion and their bioactivities. J. Funct. Foods 2018, 46, 57-65. [CrossRef]

20. Chandrasekara, A.; Shahidi, F. Bioaccessibility and antioxidant potential of millet grain phenolics as affected by simulated in vitro digestion and microbial fermentation. J. Funct. Foods 2012, 4, 226-237. [CrossRef]

21. Mosele, J.I.; Macià, A.; Romero, M.P.; Motilva, M.J. Stability and metabolism of Arbutus unedo bioactive compounds (phenolics and antioxidants) under in vitro digestion and colonic fermentation. Food Chem. 2016, 201, 120-130. [CrossRef]

22. Bouayed, J.; Hoffmann, L.; Bohn, T. Total phenolics, flavonoids, anthocyanins and antioxidant activity following simulated gastro-intestinal digestion and dialysis of apple varieties: Bioaccessibility and potential uptake. Food Chem. 2011, 128, 14-21. [CrossRef]

23. Mackie, A. Insights and gaps on protein digestion. Curr. Opin. Food Sci. 2020, 31, 96-101. [CrossRef] 
24. Velickovic, T.D.C.; Stanic-Vucinic, D.J. The role of dietary phenolic compounds in protein digestion and processing technologies to improve their antinutritive properties. Compr. Rev. Food Sci. Food Saf. 2018, 17, 82-103. [CrossRef] [PubMed]

25. Huang, F.; Hong, R.Y.; Yi, Y.; Bai, Y.J.; Dong, L.H.; Jia, X.C.; Zhang, R.F.; Wang, G.J.; Zhang, M.W.; Wu, J. In vitro digestion and human gut microbiota fermentation of longan pulp polysaccharides as affected by Lactobacillus fermentum fermentation. Int. J. Biol. Macromol. 2020, 147, 363-368. [CrossRef] [PubMed]

26. Carnachan, S.M.; Bootten, T.J.; Mishra, S.; Monro, J.A.; Sims, I.M. Effects of simulated digestion in vitro on cell wall polysaccharides from kiwifruit (Actinidia spp.). Food Chem. 2012, 133, 132-139. [CrossRef]

27. Yuan, Q.; He, Y.; Xiang, P.Y.; Wang, S.P.; Cao, Z.W.; Gou, T.; Shen, M.M.; Zhao, L.; Qin, W.; Gan, R.Y.; et al. Effects of simulated saliva-gastrointestinal digestion on the physicochemical properties and bioactivities of okra polysaccharides. Carbohydr. Polym. 2020, 238, 116183. [CrossRef] [PubMed]

28. Wang, W.J.; Ma, X.B.; Jiang, P.; Hu, L.L.; Zhi, Z.J.; Chen, J.L.; Ding, T.; Ye, X.Q.; Liu, D.H. Characterization of pectin from grapefruit peel: A comparison of ultrasound-assisted and conventional heating extractions. Food Hydrocolloids. 2016, 61, 730-739. [CrossRef]

29. Zhang, Z.Z.; Wang, X.M.; Liu, C.B.; Li, J.F. The degradation, antioxidant and antimutagenic activity of the mucilage polysaccharide from Dioscorea opposita. Carbohydr. Polym. 2016, 150, 227-231. [CrossRef]

30. Zhang, M.; Mu, T.H. Optimisation of antioxidant hydrolysate production from sweet potato protein and effect of in vitro gastrointestinal digestion. Int. J. Food Sci. Tech. 2016, 51, 1844-1850. [CrossRef]

31. Jiang, S.S.; Liu, L.; Xu, J.J.; Zeng, M.Y.; Zhao, Y.H. Amino acid composition and digestibility of Pacific oyster (Crassostrea gigas) proteins isolated from different parts. LWT Food Sci. Technol. 2019, 116, 108591. [CrossRef]

32. Yuan, Q.; He, Y.; Xiang, P.Y.; Huang, Y.J.; Cao, Z.W.; Shen, S.W.; Zhao, L.; Zhang, Q.; Qin, W.; Wu, D.T. Influences of different drying methods on the structural characteristics and multiple bioactivities of polysaccharides from okra (Abelmoschus esculentus). Int. J. Biol. Macromol. 2020, 147, 1053-1063. [CrossRef]

33. Tsao, R. Chemistry and biochemistry of dietary polyphenols. Nutrients 2010, 2, 1231-1246. [CrossRef] [PubMed]

34. Zou, L.; Wu, D.T.; Ren, G.-X.; Hu, Y.C.; Peng, L.X.; Zhao, J.L.; Garcia-Perez, P.; Carpena, M.; Prieto, M.A.; Cao, H.; et al. Bioactive compounds, health benefits, and industrial applications of Tartary buckwheat (Fagopyrum tataricum). Crit. Rev. Food Sci. Nutr. 2021, 1-17. [CrossRef] [PubMed]

35. Zhu, R.G.; Wang, C.Y.; Zhang, L.J.; Wang, Y.; Chen, G.; Fan, J.G.; Jia, Y.F.; Yan, F.W.; Ning, C. Pectin oligosaccharides from fruit of Actinidia arguta: Structure-activity relationship of prebiotic and antiglycation potentials. Carbohydr. Polym. 2019, $217,90-97$. [CrossRef] [PubMed]

36. Zhao, P.; Li, X.; Wang, Y.; Zhang, X.Q.; Jia, H.; Guo, L.P.; Huang, L.Q.; Gao, W.Y. Comparative studies on characterization, saccharide mapping and antiglycation activity of polysaccharides from different Polygonatum ssp. J. Pharm. Biomed. Anal. 2020, 186, 113243. [CrossRef]

37. Pantidos, N.; Boath, A.; Lund, V.; Conner, S.; McDougall, G.J. Phenolic-rich extracts from the edible seaweed, ascophyllum nodosum, inhibit $\alpha$-amylase and $\alpha$-glucosidase: Potential anti-hyperglycemic effects. J. Funct. Foods 2014, 10, 201-209. [CrossRef]

38. Wu, D.T.; He, Y.; Fu, M.X.; Gan, R.Y.; Hu, Y.C.; Peng, L.X.; Zhao, G.; Zou, L. Structural characteristics and biological activities of a pectic-polysaccharide from okra affected by ultrasound assisted metal-free Fenton reaction. Food Hydrocoll. 2022, $122,107085$. [CrossRef] 